九州大学学術情報リポジトリ

Kyushu University Institutional Repository

\title{
Amidations of Rosin with Isocyanates
}

\section{Wu, Zong-Hua}

Laboratory of Industrial Chemistry of Wood, Faculty of Agriculture, Kyushu University

\section{Tanaka, Hiroo}

Laboratory of Industrial Chemistry of Wood, Faculty of Agriculture, Kyushu University

https://doi.org/10.5109/24133

出版情報: 九州大学大学院農学研究院紀要. 41 (1/2)，pp.83-89，1996-11. Kyushu University バージョン：

権利関係 : 


\title{
Amidations of Rosin with Isocyanates*
}

\author{
Zong-Hua Wu and Hiroo Tanaka \\ Laboratory of Industrial Chemistry of Wood, Faculty of Agriculture, \\ Kyushu University, Fukuoka 812-81, Japan \\ (Received July 31, 1996)
}

\begin{abstract}
Amidations of abietic acid and rosin with isocyanates, a novel approach to modify rosin, were investigated using three isocyanates, namely cyclohexyl isocyanate, phenyl isocyanate, and tollyl isocyanate. The experimental results demonstrate that abietic acid and rosin reacted with the three isocyanates at 100 to $150{ }^{\circ} \mathrm{C}$ for 1 to $5 \mathrm{~h}$ to produce rosin amides in yields of 90 to $100 \%$. The reaction temperatures were much lower than 200 to $300{ }^{\circ} \mathrm{C}$ at which conventional modifications of rosin are carried out. The amidation of abietic acid with phenyl isocyanate in toluene proceeded much faster than that in acetone or dioxane. The addition of triethylamine or N-methylpiperidine as a catalyst greatly accelerated the amidation rates of abietic acid and rosin with phenyl isocyanate. Molten rosin could react, with phenyl isocyanate without using a solvent, which can shorten synthetic route of rosin amides, and reduce reaction times. The rosin amides prepared under these conditions were in light color, and suffered from little oxidation and decarboxylation.
\end{abstract}

\section{INTRODUCTION}

Rosin is a biochemical material derived from some coniferous trees, and has found wide applications in paper, ink, adhesive, coating and paint industries. In the paper industry, rosin with alum has been used as a dominant sizing agent to provide paper and paperboard with resistance to liquid wetting, penetration, and absorption since 1807. However, this familiar rosin sizing is effective only under acidic conditions, and is meeting the problem as $\mathrm{pH}$ values in papermaking systems, in recent years, are rapidly shifting from acidic to neutral-alkaline regions. Although many neutral rosin sizes were developed for the neutral-alkaline papermaking systems (Nakajima, 1993; Zhu et al., 1994; Tahara et al., 1996), few of them were successful in the industrial application for economic and technologic reasons.

One of the reasons for the difficulties to prepare practical neutral rosin sizes is that rosin esters, which are the major components for the neutral rosin sizes, have to be produced at very high reaction temperatures (Hind et al., 1954; Huang, 1994). The major component of rosin is a family of tricyclic acid called rosin acid. Abietic acid as shown in Fig. 1 is a typical structure of the rosin acids. Owing to steric hindrance of the large hydrophobic bulk in the rosin acids, the reactions of the carboxyl groups with other compounds are usually carried out at high temperatures $\left(\mathrm{ZOO}-300^{\circ} \mathrm{C}\right)$ for $3-15 \mathrm{~h}$. Furthermore, abietic acid has a conjugated double bond, and is a tertiary carboxyl acid. The high reaction temperatures for long reaction times consume a large amount of

\footnotetext{
* This paper is Part II of the series: Studies on Neutral Rosin Sizing.
} 


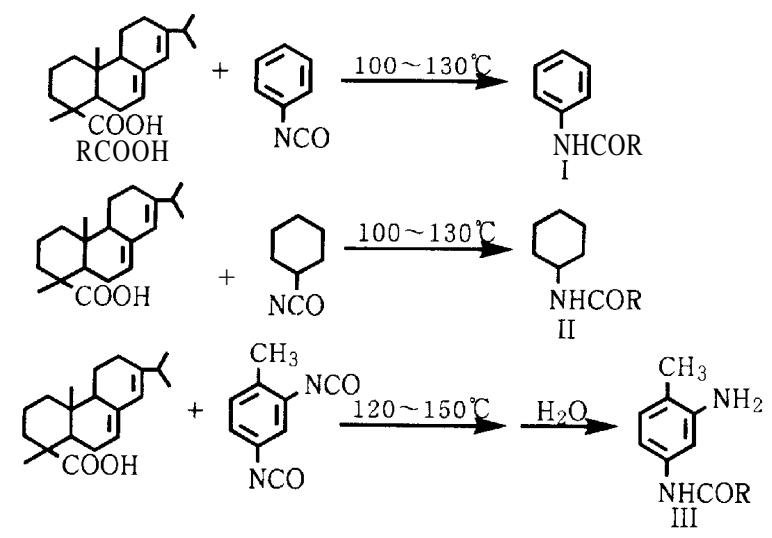

Fig. 1. The amidations of abietic aicd with isocyanates applied in this study.

energy, and may cause oxidation and decarboxylation of rosin acids. The modification of rosin at lower reaction temperatures, therefore, is a key technique to produce neutral rosin sizes, and has been the subject of many studies (Zhou et al., 1984; Wu and Tanaka, 1995).

Considering the large steric hindrance of rosin acids, rosin was allowed to react with isocyanates with high reactivity at moderate reaction temperatures. Figure 1. shows the scheme of amidations of abietic acid with three isocyanates, phenyl isocyanate, cyclohexyl isocyanate, and tollyl diisocyanate, to give Amides I, II, and III. The amidation yields of abietic acid with the three isocyanates were 90 to $95 \%$ at 100 to $150^{\circ} \mathrm{C}$ in the reaction times of 1 to $3 \mathrm{~h}$. These results illustrate that the amidation of rosin with isocyanates, that is, a novel modification of rosin could proceed well at lower reaction temperatures as expected. The rosin amides had been applied to neutral rosin sizes, and exhibited good sizing effectivenesses in the region of $\mathrm{pH} 4$ to 8 (Wu and Tanaka, 1996). In this paper, we will describe the amidation of abietic acid and rosin with phenyl isocyanate under various reaction conditions in details.

\section{MATERIALS AND METHODS}

\section{Materials}

A Chinese gum rosin (Grade W) was kindly provided by Arakawa Chem. Ind. Co. Ltd. Abietic acid $(>70 \%)$ was obtained from Tokyo Kasei Ind. Co. Ltd., and purified on a silica column using a mixture of n-hexane, ethyl acetate and methanol (6:4:1 in volume) as a eluting solvent. Cyclohexyl isocyanate, phenyl isocyanate, and tollyl diisocyanate $(>98 \%$, Tokyo Kasei Ind. Co. Ltd.) were used for the amidations without purification.

\section{Analytical procedures}

Mass spectra (MS) were recorded on a Shimazu QP-1000 gas chromatography mass 
spectrometer operating under DI conditions $(70 \mathrm{eV})$. Infrared spectra were obtained using a Perkin-Elmer system 2000 Fourier-transform spectrometer. High performance liquid chromatography (HPLC) was carried out on a JASCO TRIROTAR-II with a column of DEVELOSIL-60-3 ( $\phi 20 \times 250 \mathrm{~mm}$ ) using a mixture of n-hexane, ethyl acetate and methanol (6:4:1 in volume) as a eluting solvent. Quantitative analyses were made on the HPLC. Abietic acid and phenyl abietic amide were used as standard materials. Color of rosin amides was measured according to JIS K5902.

\section{General procedure for preparation of rosin amides}

The solvents were distilled and stored in the containers containing molecular sieve 5A. All of glasswares were dried in a oven at $105{ }^{\circ} \mathrm{C}$ overnight.

To a $200 \mathrm{ml}$ three-necked flask, desired amounts of abietic acid, a catalyst and a solvent were charged, and a condenser with $\mathrm{CaCl}_{2}$ dryer and a thermometer were equipped. The flask was heated in a oil bath to desired temperatures, and then phenyl isocyanate was added dropwise over $15 \mathrm{~min}$ with stirring. The reaction was carried out under an atmosphere of nitrogen. The samples were taken at desired times and analyzed by the HPLC. After the reaction was completed, the flask was cooled to room temperature, and the reaction mixture was washed with $0.1 \mathrm{~N} \mathrm{NaOH}$ solution, dried over $\mathrm{Na}_{2} \mathrm{SO}_{4}$, and filtered. The solvent in the filtrate was evaporated under vacuum to give the product.

In the case that phenyl isocyanate was reacted with rosin, a $200 \mathrm{ml}$ four-necked flask equipped with the condensator, the thermometer, and a glass stirrer was used. Rosin and a catalyst were charged to the flask, and heated to melten state. Then phenyl isocyanate was added dropwise over $15 \mathrm{~min}$ with stirring, and the flak was heated to required temperatures. After the reactions were carried out under an atmosphere of nitrogen for desired times, the reaction mixture was cooled to room temperature, and stored for applications.

\section{Identification of rosin amide I}

The chemical structure of rosin amide is shown in Fig. 1. Because rosin, even the abietic acid used, is a mixture of tricyclic acids as mentioned above, it is difficult to identify the rosin amide with a NMR spectroscopy. The structure of Amide I was determined by MS and IR spectroscopy. MS $m / z(\%): 377\left(\mathrm{M}^{+}, 21\right), 285(9), 258(14), 257$ (6), $241(7), 174(13), 120$ (4), 119 (100), 92 (48), 77 (26), 65 (18), 45 (17), and 43 (12). IR $\ell^{\prime}{ }_{\max } \mathrm{cm}^{-1}: 3302(\mathrm{NH}), 1670$ (amide), 1510 (phenyl), and 1158 (CON).

\section{RESULTS AND DISCUSSION}

\section{Effects of temperature and solvent on the amidation of abietic acid with phenyl isocyanate}

Table 1 gives amidation yields of abietic acid with phenyl isocyanate in four different solvents, namely acetone, dioxane, ethyl acetate, and toluene, at different temperatures. The reactions in acetone and dioxane at $25{ }^{\circ} \mathrm{C}$ proceeded very slowly. The amidation yields of abietic acid in the two solvents for $24 \mathrm{~h}$ were only $6.5 \%$ and $4.3 \%$, respectively. 
The reaction in toluene went best of the four solvents used. The yield of Amide in toluene was $26.1 \%$ after reaction at $25{ }^{\circ} \mathrm{C}$ for $3 \mathrm{~h}$, and increased to $45.2 \%$ for $24 \mathrm{~h}$. These results indicate that solvents greatly influence the amidation rates. The efficiency of the solvents used were higher in the order of toluene>ethyl acetate>acetone>dioxane. This is agreement with the results in the reactions of a phenyl isocyanate with alcohols in these solvents (Arnold et al., 1957; Ephraim et al., 1958).

Table 1. The amidation yields of abietic acid with phenyl isocyanate in the different solvents.*

\begin{tabular}{|c|c|c|c|c|c|}
\hline \multirow[b]{2}{*}{ Solvent } & \multirow{2}{*}{$\begin{array}{c}\text { Reaction } \\
\text { temperature }(\mathrm{C})\end{array}$} & \multicolumn{4}{|c|}{ Amidation yield $(\%)$} \\
\hline & & Reaction time (h) & 3 & 8 & 24 \\
\hline \multirow{2}{*}{ Acetone } & 25 & & 2.5 & 3.7 & 6.5 \\
\hline & 50 & & 7.9 & 9.2 & 14.3 \\
\hline \multirow[t]{2}{*}{ Dioxane } & 25 & & 2.0 & 2.5 & 4.3 \\
\hline & 105 & & 21.4 & 43.2 & 73.0 \\
\hline \multirow[t]{2}{*}{ Ethyl acetate } & 25 & & 7.8 & 10.2 & 14.3 \\
\hline & 75 & & 24.1 & 38.5 & 69.4 \\
\hline \multirow[t]{3}{*}{ Toluene } & 25 & & 26.1 & 31.3 & 45.2 \\
\hline & 75 & & 42.3 & 65.7 & 80.5 \\
\hline & 105 & & 64.3 & 90.3 & 100 \\
\hline
\end{tabular}

* Abietic acid and phenyl isocyanate were in equimolar amounts.

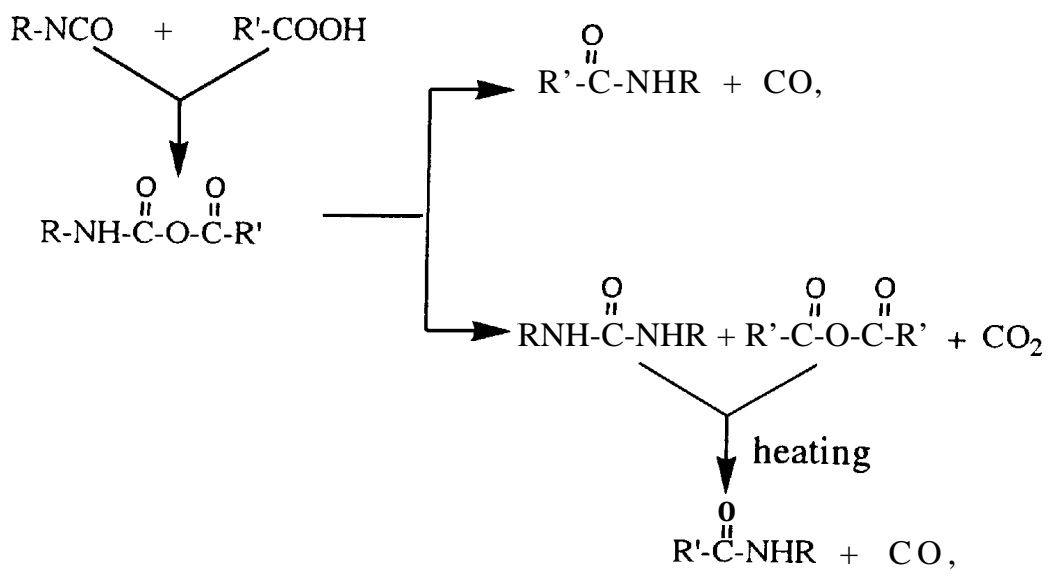

(A)

(B)

Fig. 2. Proposed mechanisms of reactions of an isocyanate with a carboxylic acid in equimolar amounts. 
The results described above show that though phenyl isocyanate is considerably reactive, it can not react with abietic acid easily at room temperature. By raising reaction temperatures, the amidation rates of abietic acid with phenyl isocyanate in the four solvents were enhanced remarkably. As shown in Table 1, the amidation yield of abietic acid with the isocyanate in toluene for $3 \mathrm{~h}$ increased from $26.1 \%$ at $25^{\circ} \mathrm{C}$ to $42.3 \%$ at 75 ${ }^{\circ} \mathrm{C}$, and $64.3 \%$ at $105^{\circ} \mathrm{C}$. Figure 2 shows proposed mechanisms of the reaction of an isocyanate with a carboxylic acid in equimolar amounts (Agre et al., 1955; Sorenson, 1959). The first product of the reaction is a carbamic-carboxylic anhydride which is unstable in most cases. The decomposition of the anhydride proceeds through two paths to give a amide in (A), and a symmetrical urea and the anhydride of the acid in (B). Carbon dioxide is evolved in both cases. The products of path (B) can react with each other on heating to give the amide in path (C). Thus, under severe conditions, the ultimate product of the reaction is the amide. However, considering oxidation and decarboxylation of rosin at high reaction temperatures, the suitable temperatures for the amidations of rosin with isocyanates were 100 to $150^{\circ} \mathrm{C}$ as stated in following sections.

\section{Catalyzed amidation of abietic acid with phenyl isocyanate}

From the data in Table 1, it can be seen that the amidation of abietic acid with phenyl isocyanate in toluene even at $105^{\circ} \mathrm{C}$ had to be carried out for more than $8 \mathrm{~h}$ to obtain the products in amidation yields of above 90\%. To reduce reaction times, catalyzed amaidation of abietic acid with phenyl isocyanate was tried. It is well known that reactions of alcohols with an isocyanate were catalyzed by tertiary amines (Burkus, 1961; Milena et al., 1994). Therefore, two typical tertiary amines, triethylamine and $\mathrm{N}$ methylpiperidine which showed large catalysis activity in the reactions of the alcohols with the isocyanate, were chosen for the amidation of abietic acid with phenyl isocyanate.

The catalyzed amidations were carried out in toluene at $105^{\circ} \mathrm{C}$ and the results were given in Table 2. The addition of triethylamine or $\mathrm{N}$-methylpiperidine $(10 \mathrm{mg} / \mathrm{g}$ abietic acid) reduced the reaction times from $10 \mathrm{~h}$ without the catalysts to $3 \mathrm{~h}$ to reach amidation yields of about $95 \%$. The catalysis activity of $\mathrm{N}$-methylpiperidine was a little larger than

Table 2. Catalyzed amidations of abietic acid with phenyl isocyanate in toluene at $105{ }^{\circ} \mathrm{C}$.

\begin{tabular}{ccrc}
\hline Catalyst & $\begin{array}{r}\text { addition amount } \\
\text { (mg/g abietic acid) }\end{array}$ & $\begin{array}{r}\text { Reaction time } \\
\text { (h) }\end{array}$ & $\begin{array}{r}\text { Amidation yield } \\
(\%)\end{array}$ \\
\hline- & - & 10 & 94 \\
Trierthylamine & 5 & 3 & 85 \\
& 10 & 3 & 93 \\
N-methyl & 20 & 3 & 95 \\
piperidine & 5 & 3 & 89 \\
& 10 & 3 & 95 \\
& 20 & 3 & 98 \\
\hline
\end{tabular}

* Abietic acid and phenyl isocyanate were in equimolar amounts. 
that of triethylamine. No significant difference in catalysis efficiency could be observed for the addition amounts of the catalysts between 10 and $20 \mathrm{mg} / \mathrm{g}$ abietic acid. The results demonstrate that the tertiary amines can greatly accelerate the reaction rate of abietic acid with phenyl isocyanate.

\section{Amidation of rosin with phenyl isocyanate}

Table 3 shows the results of amidation of rosin with phenyl isocyanate in toluene. Based on the comparison of the data in Table 3 with those in Tables 1 and 2, it is found that the amidation of rosin with phenyl isocyanate could also proceeded well, but a little slower rate than that of abietic acid with the isocyanate. For example, rosin and abietic acid reacted with phenyl isocyanate in toluene for $11 \mathrm{~h}$ and $10 \mathrm{~h}$ to reach the amidation yields of $95 \%$ and $94 \%$, respectively. This may be because rosin is a mixture of tricyclic acids including abietic acid which have different amidation rates.

On the other hand, rosin melts at about $90^{\circ} \mathrm{C}$. If molten rosin may react directly with an isocyanate without using a solvent, the synthetic route for rosin amide can be shortened, and the cost for industrial production of the amide can be cut down. The experimental data in Table 3 shows that rosin reacted with the isocyanate at $105{ }^{\circ} \mathrm{C}$ for $7 \mathrm{~h}$ to give amidation yield of $91 \%$ compared with $95 \%$ for $11 \mathrm{~h}$ for the reaction in toluene. By rasing reaction temperature to $200^{\circ} \mathrm{C}$, the reaction time to give product with the same amidation yield was reduced to $1 \mathrm{~h}$. The addition of $\mathrm{N}$-methyl piperidine greatly accelerated the amidation rate of rosin with phenyl isocyanate. These results proved that rosin can react with phenyl isocyanate well without using a solvent as expected.

Table 3. The amidation yields of rosin with phenyl isocyanate*.

\begin{tabular}{|c|c|c|c|c|c|}
\hline \multicolumn{4}{|c|}{ Reaction conditions } & \multirow{2}{*}{$\begin{array}{c}\text { Amidation } \\
\text { yield } \\
(\%)\end{array}$} & \multirow{2}{*}{$\begin{array}{c}\text { Color } \\
\text { number }\end{array}$} \\
\hline Solvent & Catalyst & $\begin{array}{c}\text { Temperature } \\
\left({ }^{\circ} \mathrm{C}\right)\end{array}$ & $\begin{array}{r}\text { Time } \\
\text { (h) }\end{array}$ & & \\
\hline Toluene & _ & 105 & 11 & 95 & 35 \\
\hline Toluene & Triethylamine & 105 & 4 & 94 & 25 \\
\hline Toluene & $\begin{array}{l}\text { N-Methyl- } \\
\text { piperidine }\end{array}$ & 105 & 3 & 94 & 25 \\
\hline \multicolumn{6}{|l|}{-} \\
\hline - & - & 105 & 7 & 91 & 35 \\
\hline - & _ & 150 & 4 & 92 & 50 \\
\hline \multirow[t]{2}{*}{ - } & N-Methyl- & 200 & 1 & 92 & $>70$ \\
\hline & piperidine & 150 & 1 & 93 & 35 \\
\hline
\end{tabular}

$* \mathrm{COOH} / \mathrm{NCO}=1$ 


\section{Oxidation and decarboxylation of rosin during the amidation}

Color is an important indication of modified rosin products, which somewhat reflects oxidation of rosin (Hind et al. 1954; Nakamura, 1970). In this study, we used color number according to JIS K5902 to monitor color changes of the reaction products of rosin with phenyl isocyanate as shown in Table 3. The unmodified rosin melted at about $90^{\circ} \mathrm{C}$, and had the color number of 10 . The data in Table 3 shows that the color numbers of the rosin amide prepared at $105^{\circ} \mathrm{C}$ were smaller than 35 , indicating that oxidation occurred during the amidation was small. But the color number of the modified product was dramatically increased to $>70$ when the amidation temperature was $200^{\circ} \mathrm{C}$. It was observed that the color of reaction mixtures rapidly became darken at about $180^{\circ} \mathrm{C}$. Thus, it is important to control the reaction temperature below $150^{\circ} \mathrm{C}$ in order to obtain light colored products.

The results of HPLC separation of the reaction mixtures produced at $105^{\circ} \mathrm{C}$ revealed that the amounts of decarboxylated products were below $1 \%$, but increased to $3 \%$ for the products made at $200^{\circ} \mathrm{C}$, which meant that the decarboxylation in the amidation of rosin with phenyl isocyanate was small. This is consistent with the results that significant decarboxylation of rosin usually occur at above $220{ }^{\circ} \mathrm{C}$ (Hind et al. 1954).

\section{REFERENCES}

Agre, C. L., G. Dinga and R. Rflaum 1955 Organic anti-foaming agents. J. Org. Chem., 20: 695-699

Arnold, R. G., J. A. Nelson and J. J. Verbance 1957 Recent advances in isocyanate chemistry. Chem. Revs., 57: 47-76

Burkus, J. 1961 Tertiary amine catalysis of the reaction of phenyl isocyanate with alcohols. J. Org. Chem., 26: 1779-1782

Ephraim, S., A. E. Woodward and R. B. Mesrobian 1961 Kinetic studies of the reaction of phenyl isocyanate with alcohols in various solvents. J.Am. Chem. Soc., 80: 1326-1328

Hind, J. D., T. T. Kanno and C. C. Miner 1954 Ester gum by esterifications of rosin with glycerol. Ind. Eng. Chem., 46: 440-452

Huang, X.-h. 1994 Cerium sulfate used as catalyst for rosin esterifications. Forest Prod. Chem. Ind., 14(1): $57-60$

Milena, S., K. Miroslav, S. Pavel, K. Ivan and D. Karel, 1994 Cyclotrimerization of isocyanate groups: catalyzed reaction of phenyl isocyanate. J.Appl.Polym.Sci., 52: 895-904

Nakamura, N. 1970 "Paper sizing", Kitao Book Trade Co., Osaka, pp448-449

Nakajima, M. 1993 Rosin based and new material based neutral sizing agents. Japan Tappi, 47: 589-593

Sorenson, W. R. 1959 Reaction of isocyanate and a carboxylic acid in dimethyl sulfoxide. J. Org. Chem. 24: $978-980$

Tahara, T., K. Matsushima and 0. Koguchi 1996 The new neutral sizing agent. Japan Tappi, 50: 120-127

Wu Z.-h. and H. Tanaka 1995 Behaviors of polyvinylamines in neutral rosin sizing. Mokuzai Gakkaishi, 41: 91 1-916

Wu Z.-h. and H. Tanaka 1996 Application of rosin amides to sizing under neutral papermaking condition. Forest Prod. Ind. Chem., 16(3):15-20

Zhou, D.-b., Y. Endo and R. Oye 1984 Studies on the neutral synthetic size from rosin. Japan Tappi, 38: $1127-1135$

Zhu Y.-q., L.-s. Xie and Y.-q. Long 1994 Study on cationic dispersed rosin neutral size. Zhonguo Zaozu, 13(12): $30-33$ 